\title{
Shifty behavior: Investigating predicates of personal taste and perspectival anaphors*
}

\author{
Elsi Kaiser \\ University of Southern California
}

\begin{abstract}
Many expressions in language are perspective-sensitive, including predicates of personal taste and some anaphoric forms. This paper reports experiments testing sentences like Nora told/heard from Amy about the frightening photograph of her/herself, with two perspective-sensitive elements, to see whether and how identification of the judge of predicates of personal taste relates to identification of the antecedent of pronouns and reflexives in picture-NPs. This allows to us test if they follow a shift-together constraint requiring them to be interpreted relative to the same perspectival center. Our results corroborate earlier findings on the source/perceiver biases of reflexives and pronouns, and reveal a strong preference to interpret the individual who is the source of information as the judge, but do not provide clear evidence for a shift-together constraint on the interpretation of PPTs and pronouns and reflexives in picture-NPs.
\end{abstract}

Keywords: predicates of personal taste, reflexives, pronouns, picture-NPs, perspective sensitivity, shift together, anaphors, subjective adjectives

\section{Introduction}

Language contains a variety of perspective-sensitive elements, e.g. predicates of personal taste (PPTs, e.g. tasty, fun), epithets (e.g. the idiot), perspective-sensitive reflexives (e.g. picture-NPs, picture of herself), and relative spatial terms (left, right). Broadly speaking, these kinds of expressions make reference to the pointof-view of an individual, sometimes referred to as the perspectival center/anchor. Many of these perspectival elements also carry information about the center's subjective evaluation of something or someone (e.g. PPTs, epithets).

This paper reports psycholinguistic experiments on English that bring together two types of perspective-sensitive elements, namely PPTs like fun and frightening and anaphoric expressions such as herself/himself that have been argued, in certain syntactic configurations, to be perspective-sensitive. The experiments use sentences like $(1 \mathrm{a}, \mathrm{b})$, and investigate whether people's interpretation of whose

\footnotetext{
* I would like to thank the SALT 30 audience for useful comments and feedback. This material is based upon work supported by the National Science Foundation under grant no. BCS-1749612.
} 
opinion the PPT expresses is correlated with their interpretation of who the reflexive or pronoun refers to. Is there a relation between the antecedent of the pronoun or reflexive and the opinion-holder of the PPT? Do they 'shift together'? I first report an experiment testing sentences like (1a), as well as a follow-up study, and then turn to a second follow-up experiment using sentences like (1b), where the pronoun and the reflexive are in different tensed clauses.

(1) a. Kate told/heard from Lisa about the funny photograph of her/herself.

b. Kate told/heard from Lisa that there was a funny photograph of her/herself in the newspaper.

The remainder of Section 1 provides background on the judge dependence of predicates of personal taste (PPTs) and the perspective-sensitivity of anaphors, focusing in particular on picture-NPs. In Section 2, I discuss claims that PPTs and perspective-sensitive anaphors - at least when they are in the same local domain are interpreted relative to the same perspectival center. Section 3 reviews our earlier experimental work on pronouns and reflexives in picture-NPs (without PPTs). Sections 4 through 6 present the main experiment which offers a systematic investigation of how the interpretation of reflexives and pronouns in picture-NPs in English relates to the interpretation of PPTs modifying the picture-NP. In Section 7 , I report two follow-up studies that address potential questions concerning the conclusions of the main experiment. The paper concludes with Section 8.

\subsection{Predicates of personal taste}

Let's consider the first perspective-sensitive ingredient in the current investigation: Predicates of personal taste (PPTs), e.g. tasty, frightening, fun and amazing, express subjective opinions anchored to an opinion-holder. They express an individual's point-of-view/perspective (see Pearson 2013, Moltmann 2010 on generic uses). According to Lasersohn (2005), they contain a judge parameter $j$, such that the truth value of an utterance like (2a) is relativized to a judge $(2 \mathrm{~b})$, by default the speaker.

(2) a. Cross-country skiing is fun.

b. $[[\text { fun }]]^{c ; w, t, j}=[\lambda x \cdot x$ is fun for $j$ in $w$ at $t]$

The current work does not aim to distinguish between different accounts of PPTs (e.g. Glanzberg 2007, Stephenson 2007, Anand 2009, Cappelen \& Hawthorne 2009, Snyder 2013, Bylinina 2014, Coppock 2018, Zakkou 2019, Willer \& Kennedy 2020, i.a.). What matters for us is that PPTs are in some way judgedependent - interpreted relative to an opinion-holder. Given its widespread use, the term 'judge' is used below atheoretically to refer to the opinion-holder; this paper does not aim to address the contextualist vs. relativist debate. 
A property of PPTs relevant for the present discussion is that use of a PPT indicates that the judge needs to have first-hand experience of the relevant kind (see e.g. Pearson 2013, Ninan 2014, Bylinina 2014, McNally \& Stojanovic 2017, i.a.). For example, if I say (2a), this suggests that I have the right kind of first-person experience that allows me to judge cross-country skiing to be fun. In other words, PPTs entail that the judge is an experiencer, "a sentient individual who perceives the property in question" (McNally \& Stojanovic 2017:24). The role of the sentient experiencer is also discussed by Bylinina (2014): "A direct statement about someone's internal state can be made only if the judge parameter is set to the same value as the experiencer of this internal state" (Bylinina 2014:58). In her semantics for tasty (3), part (ii) states that the judge $j$ and experiencer $z$ refer to the same individual. Like McNally \& Stojanovic (2017), Bylinina (2014) distinguishes PPTs like tasty that refer to experience from subjective adjectives like smart/healthy which she argues do not refer to experience in the same way. The judge/experiencer relation has been explored in depth, from a variety of perspectives, in several recent papers (e.g. Kennedy \& Willer 2016, Sæbø 2009, Pearson 2013, Ninan 2014).

$\llbracket \operatorname{tasty} \rrbracket^{c ; w, t, j}=$

(i) $\lambda z \lambda x$ : $\exists s\left[\operatorname{taste}(s) \& \operatorname{Experiencer}(s ; z) \& \operatorname{Stimulus}(s ; x) \& \operatorname{TASTE}(s)>d_{\text {st }}\right.$ for $j$ at $t$ in $w$; (ii) JUDGE=EXPERIENCER: $j=z$

The sentences in the experiments reported in this paper are like $(1 \mathrm{a}, \mathrm{b})$, with the verbs told and heard. In (1a,b), the most plausible judge for the PPT is presumably the individual who is the source of information (subject of told, object of heard). This is because that individual can be inferred to have the relevant first-hand experience of the photograph that allows them to evaluate it as funny, frightening etc. (Alternatively, the first-person speaker could also be construed as the judge.) I return to this when outlining the predictions for the experiments in Section 4.

\subsection{Perspective-sensitive anaphors}

We now turn to the second ingredient of the current investigation: perspectivesensitive anaphors. ${ }^{1}$ The term logophoricity is often used to refer to a situation where 'the 'perspective' of an internal protagonist of a sentence or discourse, as opposed to that of the current, external speaker, is being reported by some morphological and/or syntactic means" (Huang 2000:172-173). Some languages (e.g. Ewe, Donno So) have a morphologically distinct class of specialized logophoric pronouns used to refer to the 'subject of consciousness', the person whose speech, thoughts or feelings are being reported (e.g. Hagège 1974, Clements

\footnotetext{
${ }^{1}$ In this paper, I use the term 'anaphors' to refer to both reflexives and pronouns.
} 
1975, Sells 1987, Culy 1994, Pearson 2015, Huang 2000), often referred to as the logophoric center (or perspectival center).

Although English does not have a morphologically distinct class of logophoric pronouns, it has often been noted that in some contexts, certain anaphoric forms in particular reflexives - exhibit perspective sensitivity (e.g. Cantrall 1974, Kuno 1987, Rooryck \& Vanden Wyngaerd 2011, i.a.). Although pronouns and reflexives in English are in (nearly) complementary distribution (as reflected in Binding Theory, e.g. Chomsky 1981), researchers noted early on that the complementarity of pronouns and reflexives breaks down in some contexts (e.g. Jackendoff 1972, Chomsky 1986, Williams 1987, Pollard \& Sag 1992, Reinhart \& Reuland 1993 and many others). For example, in possessorless picture-NP (ex.4), both a pronoun and a reflexive seem acceptable, although judgments are often murky.

(4) Lisa $_{\mathrm{i}}$ found a picture of her $\mathrm{i}_{\mathrm{i}} /$ herself $_{\mathrm{i}}$.

It has been noted that in a variety of contexts, use of a reflexive in a context where a pronoun also seems acceptable with the same intended referent is correlated with point-of-view and perspective-taking (e.g. Cantrall 1974, Zribi-Hertz 1989, Kuno 1987, Fludernik 1993, i.a.). In intuitive terms, many agree that reflexives in such contexts signal that what is being expressed is the point-of-view of the reflexive's antecedent (rather than the first-person speaker or narrator). Thus, one could say that the reflexive refers to the perspectival center/the logophoric center.

In the present paper, I focus specifically on pronouns and reflexives in pictureNPs, which have received extensive attention in prior theoretical work (including but not limited to Jackendoff 1972, Chomsky 1986, Williams 1987, Pollard \& Sag 1992, Reinhart \& Reuland 1993, Tenny 2004). ${ }^{2}$ There are three main reasons for selecting this construction for the current investigation of perspective sensitivity: First, picture-NPs have been extensively discussed in prior theoretical work on pronouns and reflexives. Second, as will become clear in Section 3, our prior psycholinguistic investigations on picture-NPs (Kaiser, Runner, Sussman \& Tanenhaus 2009) offer foundational data for the current study by providing experimental evidence for divergent perspectival behaviors of pronouns and reflexives in this context. Third, picture-NPs allows predicates of personal taste to co-occur with pronouns and reflexives in the same nominal structure (e.g. the funny photograph of her/herself), and thus provide a useful tool for investigating the interpretation of two kinds of perspective-sensitive expressions in close proximity.

As noted by authors like Kuno (1987), factors like point of view can influence

\footnotetext{
${ }^{2}$ This paper focuses on possessorless picture-NPs, widely regarded as perspective-sensitive. For experiments on possessed structures (e.g. Lisa's picture of her/herself), see e.g. Keller and Asudeh (2001), Runner, Sussman, \& Tanenhaus (2003), Kaiser, Runner, Sussman \& Tanenhaus (2009).
} 
whether a given referent can antecede a reflexive in a picture-NP. ${ }^{3}$ Consider (5):

(5) a. John heard from Mary $\mathrm{i}$ about a damaging rumor about herself $f_{\mathrm{i}}$ that was going around. (Kuno 1987:175)

b. ?? John told Mary ${ }_{i}$ about a damaging rumor about herself $f_{i}$ that was going around.

An antecedent that is the source of information - Mary in (5a) - can trigger use of a reflexive in a picture-NP. In contrast, when Mary is not the source of information but instead is the recipient (the one perceiving the information), the sentence sounds worse (5b). Based on these patterns, one could hypothesize that reflexives in picture-NPs prefer antecedents that are sources-of-information. I refer to this as the 'Source of information' hypothesis for reflexives. Following Sells (1987), in the present discussion we define a 'source' as the one who is the intentional agent of the communication (Sells 1987). Thus, although English has no pure logophoric pronouns of the type found in languages such as Ewe, the 'source of information' hypothesis for reflexives in picture-NPs echoes the behavior of morphologically logophoric pronouns that refer to the source of reported speech/thought (e.g. Clements 1975, Sells 1987).

Prior work suggests that not only reflexives but also pronouns in picture-NPs are sensitive to perspectival information. Let's start by considering $(6 a, b)$, from Reinhart \& Reuland (1993) (see also Jackendoff 1972, Chomsky 1986 and others). Here, (6a), where the pronoun's antecedent is a perceiver of information is reported to sound better than (6b) where the pronoun's antecedent is the source:

(6) a. Max $\mathrm{j}_{\mathrm{j}}$ heard a story about him $\mathrm{h}_{\mathrm{j}}$

b. * $\operatorname{Max}_{\mathrm{j}}$ told a story about him ${ }_{\mathrm{j}}$.

Building on these observations, Tenny (2003), who calls pronouns in this context SDPs, short-distance pronouns, notes that "verbs that provide a sentient, perceiving antecedent are especially conducive to SDPs" (Tenny 2003:14). She further specifies that "SDPs in representational contexts [....] are especially felicitous with perceiving subjects." Based on these patterns, one could hypothesize that pronouns in picture-NPs prefer antecedents that are perceivers-of-information. I refer to this as the 'Perceiver of information' hypothesis for pronouns. It is, essentially, the converse of the 'Source of information' hypothesis for reflexives.

Intriguingly, the idea that the perceiver (and not only the source) plays a privileged role is echoed by languages with morphologically distinct logophoric pronouns: Languages such as Mapun and Angas have specialized logophoric

\footnotetext{
${ }^{3}$ The term 'picture-NP' is used for structures with the noun 'picture' (e.g. picture of her / herself) as well as other kinds of representational and depictive NPs (e.g. portrait of, rumor about).
} 
pronouns referring to the addressee, the person who is receiving/perceiving the information (e.g. Frajzyngier 1993). This could be taken as evidence that both the source and the perceiver have a special status as perspectival centers.

In sum, both reflexives and pronouns in picture-NPs appear to be sensitive to perspective-related factors, but in different directions: Reflexives exhibit a preference to be interpreted as referring to the source of information, the one whose speech/thoughts are being expressed. Pronouns exhibit a preference for the perceiver of information, the one receiving the information. This reflects the two perspectives inherent in communicative information-transfer events: someone who conveys the information (source) and someone who receives it (perceiver).

\section{Bringing together two perspective-sensitive elements}

So far, we have seen that both predicates of personal taste (PPTs) and reflexives and pronouns in picture-NPs are perspective-sensitive, in a broad sense. Indeed, this paper is not the first to explore the link between PPTs' judge dependency and the perspective-sensitivity of anaphors. Stephenson (2005), in her paper on predicates of personal taste and epistemic modals, mentions the possibility of logophoric pronouns being analyzed as specialized forms that refer to the judge. Relatedly, in a paper on context-shifting effects with predicates of personal taste, indexicals and experiencer predicates, McCready (2007) agrees that "it seems very reasonable that the judge should be the same as the logophoric center (...). After all, the logophoric center is the individual whose perspective is taken, and, in some sense, the individual whose perspective is expressed is just what the judge parameter formalizes" (McCready 2007:14). Deal and O'Connor (2011) do not specifically discuss PPTs, but make use of Lasersohn's (2005) notion of judge when discussing the behavior of logophors in Northern Pomo, which they analyze as referring to the judge in exocentric contexts (where the judge is not the speaker).

In sum, then, it seems tempting to connect the perspectival center of perspective-sensitive pronouns and the judge of PPTs. A proposal along these lines - although not making specific reference to English pronouns and reflexives in picture-NPs - has been put forward by Bylinina, McCready and Sudo (2014):

Shift-Together for Perspective-sensitive items:

Perspective-sensitive items in the same 'domain' must refer to the same perspectival center. (Bylinina, McCready \& Sudo 2014)

Bylinina et al.'s term 'perspective-sensitive items' refers to a broader class of perspective-sensitive elements that includes PPTs, spatial terms, evidentials and logophoric reflexives. They argue that that there are two classes of perspectivesensitive items, evidential and pronominal, which differ in terms of whether they 
obligatory or optionally shift to a non-default individual in different contexts. Crucially, under their analysis, perspective-sensitive elements in the same domain cannot shift independently of each other: The perspectival center index can be shifted away from the speaker by the $\Pi$ operator, which binds perspective-sensitive elements in its scope to the same perspectival center. Bylinina et al. do not aim to provide a full answer to the question of what is the relevant domain within which the shift-together constraint applies. We return to this below.

A similar shift-together restriction has been proposed for indexicals (see Anand \& Nevins 2004, see also Deal 2020 and Sundaresan 2021). I follow Bylinina et al. in using the term 'shift together' when talking about the behavior of PPTs and perspective-sensitive anaphors, but I am not making claims about indexicals such as 'I' or 'you'. (For the purposes of this paper, I assume the pronouns and reflexives investigated here are anaphoric, not pure indexicals.) The relation between these two shifting phenomena, indexical shift and perspectival anaphors, is an important question, but beyond the scope of this paper (see Sundaresan 2021).

\subsection{What shifts together?}

Having introduced the idea of shift together, let's consider (8) from Bylinina et al. (2014). They note that here, the two perspective-sensitive elements talented and foreigner can both be interpreted as anchored to the speaker (a), or both as shifted to the sentence subject (b), John, but that mixed readings (c,d) are not available.

(8) John read a book by a talented foreigner.

a. I think the author is talented; author is from a different country than me

b. $\mathrm{J}$ thinks the author is talented; author is from a different country than $\mathrm{J}$

c. *I think the author is talented; author is from a different country than $\mathrm{J}$

d. *J thinks the author is talented; author is from a different country than me

However, in (9a-c), under an attitude predicate, a PPT in predicative position has the subject of think/say as its judge, while a PPT in attributive position in the same clause conveys the speaker's opinion. Here we see no shift-together, at least not on the level of the clause (see also Kneer et al. 2017). (Subscripts indicate the judge.)

(9) a. John thinks that this tasty speaker $_{\text {cake is disgusting }}$ John. $_{\text {(Pearson 2013) }}$

b. Pascal says: Mordecai thinks that the difficult ${ }_{\text {Pascal }}$ game is easy Mordecai. (Anand \& Korotkova 2016, 2020)

c. The mother snipe thinks the ugliest speaker $_{\text {baby birds are beautiful }}$ mother. (Saebo 2009) 
What about utterances with two different kinds of perspective-sensitive elements? Examples from Japanese are in (10), from Sells (1987), building on Kuno. Here, the judge of beloved is interpreted as the same referent as the antecedent of the object-position reflexive zibun 'self.' Indeed, note that in both (a) and (b), the reflexive is coreferential with the source of information (subject of told in (a) and object of heard in (b)), and the adjective beloved is anchored to the source as well. (Subscripts on anaphors indicate the antecedent.)

a. Takasi wa Taroo kara [itosii Takasi Yosiko ga zibun ${ }_{\text {Takasi }}$ o nikundeiru to] hansita

Takasi Top Taroo from [beloved Takasi $_{\text {Yosiko Subj self }}$ Takasi Obj be-hating Comp] told

'Takasi told Taroo that his beloved ${ }_{\text {Takasi }}$ Yosiko hated him Takasi'

b. Taroo wa Takasi kara [itosii Takasi $_{\text {Yosiko ga zibun }}$ Takasi o nikundeiru to] kiita

Taroo Top Takasi from [beloved ${ }_{\text {Takasi }}$ Yosiko Subj self $_{\text {Takasi }}$ Obj be-hating Comp] heard

'Taroo heard from Takasi that his beloved Takasi Yosiko hated him Takasi'

Sells notes that (10b) also allows an interpretation where the subject Taroo is the antecedent of the reflexive, and that in this case, beloved is reflects Taroo's perspective (Sells 1987:fn), further suggesting that zibun and beloved shift together.

Relatedly, Charnavel (2020) discusses the relation between reflexives and perspective-sensitive adjectives. She proposes that reflexives typically claimed to be exempt from Binding Theory are in fact bound by a prolog generated by a logophoric operator $\mathrm{OP}_{\mathrm{LOG}}$, thus satisfying Binding Principle A (see also Sloggett 2017). She posits that with an exempt anaphor, because of the semantics of the logohoric operator, "all perspectival elements of its domain must be evaluated from the first-personal perspective of its antecedent." The key observations relevant for the present paper are illustrated for French reflexives in (11), from Charnavel: The PPT in attributive position (e.g. horrible, beautiful) must have as its judge whoever the emphatic reflexive (elle-même/lui-même) refers to. Mixed perspectives are out.

(11) Loïc mistakes photos of Marie (taken from behind) for portraits of himself and finds them beautiful while Marie thinks they are horrible

a. Loïc pense que Marie espère que [les affreusesMarie photos d'elle-même Marie / *lui-même Loï vont se vendre.

'Loïc thinks that Mary hopes that [the horrible Marie photos of herself $f_{\text {Marie }}$ / *himself Loïc will sell.'

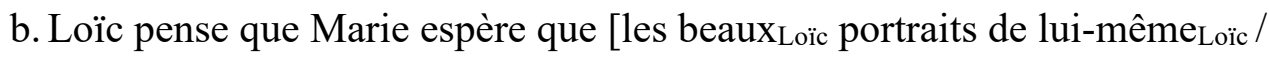


*d'elle-même $\left.{ }_{\text {Marie }}\right]$ vont se vendre.

'Loïc thinks that Mary hopes that [the beautiful Loic portraits of himself $f_{\text {Loic }} /$

*herself $f_{\text {Marie }}$ ] will sell.'

This ban on what Charnavel calls logophoric heterogeneity (aka lack of shifttogether) follows from her proposal that sentences like (11) have a logophoric operator at edge of the spellout domain, which (i) generates a covert prolog that binds the reflexive (satisfying Binding Principle A) and (ii) "imposes on its complement the first-personal perspective of the referent of its subject prolog.".

In sum, we have seen evidence that perspective-sensitive reflexives and PPTs, if they are in sufficiently close proximity, are bound to the same perspectival center. This fits with a general shift-together constraint for perspective-sensitive items (e.g. Bylinina et al. 2014). The question of what is the relevant domain in which this constraint applies not yet settled (see e.g. Bylinina et al. 2014, Charnavel 2020). The experiments presented in this paper use picture-NP constructions with the PPT adjective in attributive position (akin to (11)), in an attempt to get the relevant elements as close to each other as possible.

\subsection{Aims of this work}

The psycholinguistic work reported here brings together PPTs like fun and frightening and perspective-sensitive pronouns and reflexives in picture-NPs, in order to experimentally test interpretation of sentences like (1a) and (1b) to see whether there a relation between the antecedent of the pronoun or reflexive and the judge of the PPT. Thus, the research reported here aims to provide additional data that can complement existing observations about whether perspective-sensitive elements shift together. Experiments allow us to test these questions with a large group of participants and sentences, including a variety of PPTs. These results can provide additional data about whether PPTs and perspective-sensitive anaphors in English follow a shift-together requirement. Furthermore, as noted above, prior discussion of these issues has, to the best of my knowledge, largely focused on reflexives. Thus, the second main aim of this work is to investigate the relation between (i) PPTs and (ii) both pronouns and reflexives in picture-NPs, both of which have been argued to be perspective-sensitive. Looking at both kinds of anaphoric forms allows us to explore how the proposed source/perceiver distinction relates to the judge identification process of PPTs, and to test whether the two forms show an asymmetrical adherence to shifting along with the PPT.

\section{Psycholinguistic work on perspective-sensitive anaphors in picture-NPs}

Given that judgments concerning sentences like (4-5) are sometimes quite murky, 
we conducted a series of studies to test the validity of the hypotheses that reflexives in picture-NPs prefer perceivers of information while pronouns in picture-NPs prefer sources of information (Kaiser, Runner, Sussman \& Tanenhaus 2009). We tested sentences like (12), with pronouns or reflexives. We used the verbs told and heard from to manipulate whether the subject or object is the source or perceiver.

(12) Peter $\{$ told/heard from $\}$ John about the picture of $\{$ him/himself $\}$ on the wall.

Results from four experiments using a variety of methods, including visualworld eye-tracking and offline forced-choice questionnaires, show that yes, reflexives and pronouns in picture-NPs are sensitive to the source and perceiverof-information respectively, and this sensitivity can be detected very early on during real-time language processing. Specifically, our results show that interpretation of reflexives in picture-NPs is guided by a strong structural subject preference and a weaker but nevertheless significant source-of-information preference. We also found that interpretation of pronouns in picture-NPs is guided by a structural object preference and a strong perceiver-of-information preference. ${ }^{4}$ In sum, our prior findings suggest that both pronouns and reflexives in picture-NPs are sensitive to non-syntactic factors related to the two perspectives inherent in a communicative event, namely the source of information (preferred by reflexives) and the perceived of information (preferred by pronouns).

\section{Current experiment}

To test whether pronouns and reflexives in picture-NPs and PPTs modifying the picture-NPs need to be anchored to the same perspectival center, we conducted a series of experiments. Below, we report the first experiment in detail (Sections 4, 5 and 6), and provide brief descriptions of two follow-up experiments (Section 7).

\subsection{Participants, materials and design, procedure}

We report data from 42 self-reported U.S.-born native English speakers who completed the study over the internet. Participants were recruited from Amazon Mechanical Turk. The study was implemented using Qualtrics.

\footnotetext{
4 The verbs told and heard from differ in their syntactic structure: the object of heard from is more deeply embedded (due to from). Crucially, our results cannot be blamed on this structural difference: Participants are more likely to consider the object as a potential antecedent for a reflexive when the verb is heard from (object is more deeply embedded) than when the verb is told (object is less deeply embedded). This is the opposite of what we would expect if the results were being driven by depth of embedding. Thus, our results can't be attributed to differences in the object's depth of embedding.
} 
In target items, we manipulated (i) whether the subject or the object is the source or the perceiver by using the verbs told and heard from, and (ii) whether the pictureNP contains a reflexive, a pronoun or no anaphor, shown in (13a-c). The noanaphor condition acts as a baseline that allows us to see whether and how the source/perceiver status of the two characters influences the likelihood of their being interpreted as the judge of the PPT in the absence of any anaphoric elements.

\section{a. Reflexive:}

Nora \{told/heard from $\}$ Amy about the frightening photograph of herself.

\section{b. Pronoun:}

Nora $\{$ told/heard from $\}$ Amy about the frightening photograph of her.

\section{c. No anaphor:}

Nora $\{$ told/heard from $\}$ Amy about the frightening photograph.

In the targets, we used the noun photograph rather than picture, to minimize variation in semantic construal about what kind of depiction is being talked about. All targets used two proper names with unambiguous gender. The study consisted of 36 targets (with him/himself or her/herself), presented to participants using a Latin-Square design. The PPTs that modify the noun photograph were selected based on published work and existing semantic criteria (e.g. frightening, funny, irritating, disgusting). We used 36 different PPTs; each participant only saw each PPT once. Half the PPTs were positively-valenced (e.g. funny) and half were negatively-valenced (e.g. irritating). The study also contained 50 filler items.

Participants completed the experiment via the internet. The study used a simple force-choice question paradigm. On pronoun and reflexive trials, people first saw a screen with the critical sentence and a question about who is shown in the photograph. I refer to this as the 'who shown' question (Fig.1). This question probes the interpretation of the anaphoric expressions. On the next screen, participants again saw the critical sentence (i.e., no memory load) and a question about whose opinion the PPT conveys (Fig.1). I refer to this as the 'whose opinion' question. The answer choices are the subject of the critical sentence, the object of the critical sentence, or the narrator. On no-anaphor trials, participants were only asked the 'whose opinion' question. Participants were instructed to read the sentences as if they were reading excerpts from fiction. This was done to make the presence of a narrator plausible. The term 'narrator' was clarified in the instructions.

\subsection{Predictions}

As regards the interpretation of pronouns and reflexives in picture-NPs, I hope to replicate our earlier results which found that reflexives show a subject preference 


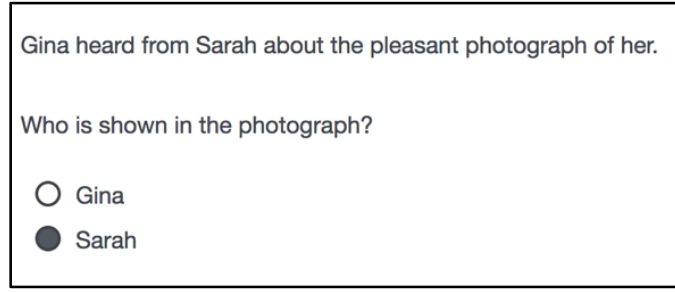

Figure 1. Left: Sample 'who shown' question (depicted after the choice 'Sarah' has already been selected). Right: Sample ‘whose opinion' question

modulated by a significant source preference, while pronouns show a clear object preference as well as a clear perceiver preference (Kaiser et al. 2009). The key question of the current experiment, however, is how these referential patterns interact with the judge identification of PPTs. In the target items, the PPT modifies the noun photograph, and the pronouns and reflexives are inside a prepositional phrase modifying the noun (see also (11) from Charnavel 2020). For now, let us make the simplifying assumption that the PPT and the pronoun/reflexive are in the same perspectival domain. (We return to this issue in the general discussion.)

If the shift-together constraint applies to the interpretation of PPTs and perspective-sensitive anaphors in picture-NPs in the kinds of sentences tested in the current experiment, both kinds of expressions should refer to the same perspectival center. In other words, (i) the antecedent of the pronoun or reflexive (which I predict will follow the patterns we observed in our earlier work) and (ii) the judge of the PPT, should coincide. For example, for $(13 a, b)$, the prediction is that whoever thinks the photograph is frightening is the person who is shown in the photograph.

However, it could be that the shift-together constraint applies selectively to some perspective-sensitive anaphors but not others. In this case, we may find that only pronouns or only reflexives shift together with PPTs. Indeed, given prior work that the judge of PPTs is the individual with the relevant first-hand experience (see e.g. Ninan 2014, McNally \& Stojanovic 2017, Bylinina 2014), we might expect the source of information in sentences like (13) to be the most likely judge: It can be inferred that the source character is the one who has the relevant first-person experience about the photograph being frightening, for example, and then conveys this to the other person. If this prediction is on the right track, we expect that the antecedent of reflexives in picture-NPs and the judge of PPTs will tend to pattern together (both prefer the source), but that the antecedent of pronouns and the judge of PPTs will diverge (since pronouns are predicted to prefer perceivers while the judge will tend to be the source, under this view). 
Finally, if the shift-together constraint does not apply to the relationship between PPTs and perspective-sensitive pronouns/reflexives, the judges of PPTs and the antecedents of anaphors are not expected to correlate in a systematic way.

\section{Results}

This section presents the responses to the 'who shown' question (anaphor resolution) and the 'whose opinion' question (PPT judge identification). The final section combines the two data types to see how choice of antecedent for the anaphoric expression relates to choice of PPT judge, to assess shift-together.

Responses to the question about who is shown in the photograph indicate who is interpreted as the antecedent of the anaphoric expression. As can be seen in the top half of Figure 2, reflexives elicit mostly subject responses, whereas pronouns are more split between subjects and objects. (The no-anaphor condition is not shown here, because it contains no anaphor.) Furthermore, this figure indicates that the two verbs do not pattern alike: The pronoun conditions show a perceiver preference: Participants are more likely to select the object with told (object $=$ perceiver) than with heard (object $=$ source). In contrast, the reflexive conditions show hints of a source preference: Participants are slightly more likely to select the subject with told $($ subject $=$ source $)$ than with heard $($ subject $=$ perceiver $)$.

Statistical analyses using mixed-effects logistic regression (glmer, R) on the proportion of structurally-expected antecedents (subjects in the reflexive conditions; objects in pronoun conditions) confirm that the subject bias of reflexives is stronger than the object bias of pronouns (main effect of anaphor type, $\mathrm{p}<.001$ ), that the verb manipulation has a significant effect (main effect of verb, $\mathrm{p}<$ 0.001 ) and that pronouns are more influenced by the verb manipulation than reflexives (anaphor type $\mathrm{x}$ verb interaction, $\mathrm{p}<0.003$ ). Further analyses confirm that pronouns elicit higher rates of object choices with told than with heard $(\mathrm{p}<.01)-$ the expected perceiver preference. In the case of reflexives, the source preference (higher rates of subject choices with told than heard) is marginal $(\mathrm{p}=0.0985)$, but goes in the same direction observed by Kaiser et al (2009). Given that Kaiser et al. (2009) also found that pronouns are more swayed by the verb manipulation than reflexives, it is not unexpected to see the same asymmetry here.

Let us now consider people's responses to the question of whose opinion it is that the photograph is frightening, funny etc: who is the PPT judge? As can be seen in the lower half of Figure 2, told conditions elicit a high proportion of 'subject's opinion' responses (black bars), while heard conditions elicit a high proportion of 'object's opinion' responses (grey bars). This suggests participants tend to interpret the source of information as the judge, in line with our prediction. 


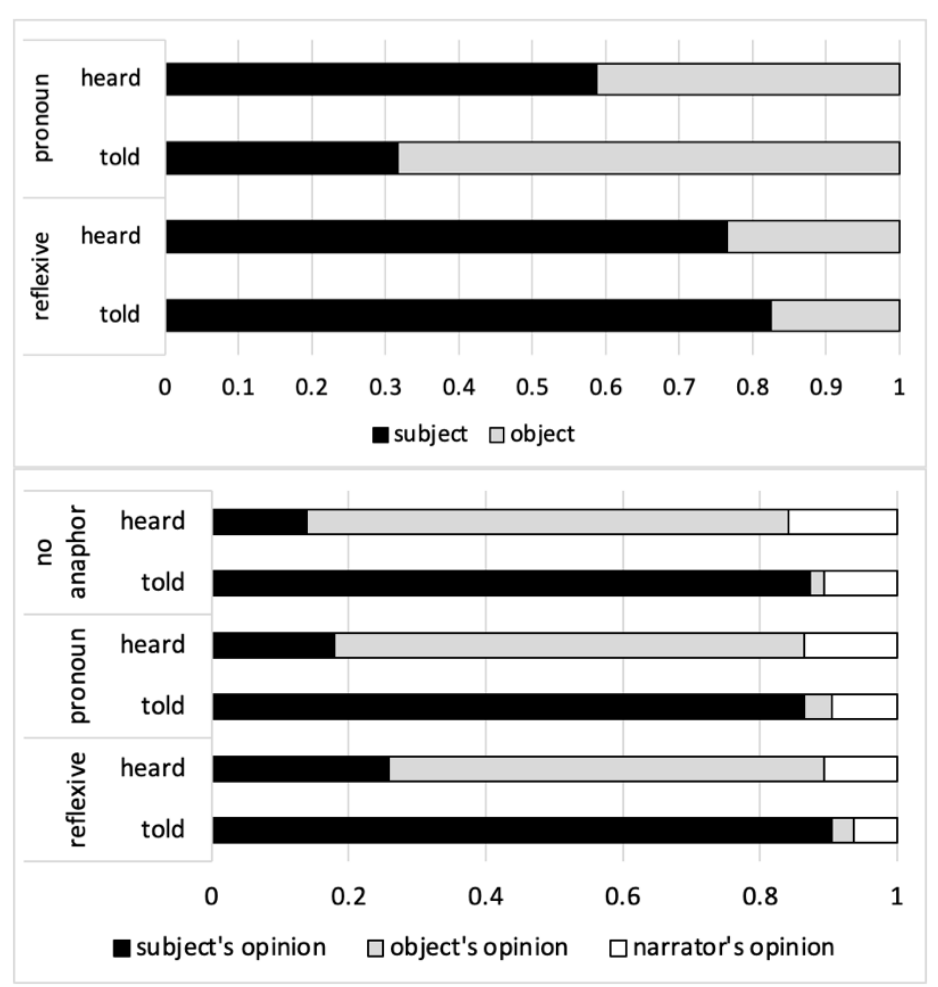

Figure 2. Upper half: Responses to 'who shown' question (anaphor resolution). Lower half: Responses to 'whose opinion' question (judge identification)

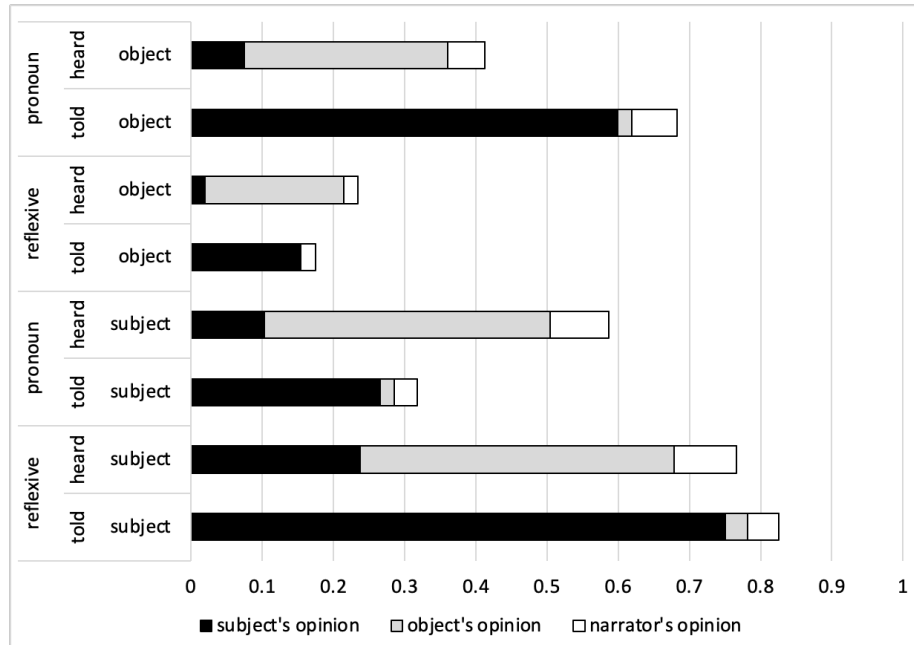

Figure 3. Combined results: 'Who shown' responses (bars) and 'whose opinion' responses (shading inside bars) 
This pattern is confirmed by statistical analyses on the proportion of 'subject's opinion' responses (glmer, emmeans with Bonferroni correction). In all three anaphor conditions (pronoun, reflexive, no anaphor), participants interpreted the PPT as having the subject as its judge more often with told than with heard (p's $<.001)$. This source preference holds regardless of what the anaphor is or whether the sentence even contains an anaphor. In other words, all three heard conditions (pronoun, reflexive, no anaphor) pattern alike, and all three told conditions pattern alike. Analyses on the proportion of 'object's opinion' responses corroborate this pattern: Participants interpreted the object as the judge more often with heard than with told, confirming the source preference. Analyses of the proportion of 'narrator's opinion' responses show no differences between conditions ( $p$ 's $>0.1$ ). Overall, the proportion of narrator opinion responses is low. This may seem surprising, since PPTs are often regarded as having a default bias for the speaker to be the judge, but my prior work (Kaiser 2015) indicates that in narrative contexts, it is easy to shift from the speaker (narrator) to a character.

In sum, participants' responses indicate that they prefer to interpret the source of information as the judge of the PPT, and that this preference is independent of whether the sentence contains an anaphor and what the anaphor is.

Figure 3 show the same information depicted in Figure 2, now combined into one graph (with the no-anaphor condition omitted). The bars show the proportion of trials where a certain anaphor was interpreted as referring to the preceding subject or object. For ease of exposition, the proportion of subject responses and the proportion of object responses are plotted separately. As mentioned earlier, reflexives mostly elicit subject interpretations, modulated by a source-ofinformation bias, whereas pronouns elicit a mix of subject and object interpretations, and show a clear perceiver bias. The segments within each bar show what proportion of responses were associated with the PPT being interpreted as the subject's opinion, object's opinion or the narrator's opinion. Recall that the source of information is preferred as the judge of the PPT. According to a strong version of shift-together, all subject-antecedent interpretations should be subject-opinion PPT interpretations: all subject-antecedent choice bars should only contain black. Similarly, all object-antecedent interpretations should be object-opinion PPT interpretations: all object-antecedent choice bars should only contain grey. However, Figure 3 shows this is clearly not the case.

\section{Discussion}

The interpretational patterns for pronouns and reflexives largely replicate our earlier findings (Kaiser et al. 2009): reflexives tend to be interpreted as referring to preceding subjects, modulated by an source preference, and pronouns exhibit both an object preference and a perceiver preference. The judge identification patterns 
for PPTs show a strong preference to interpret the source of information as the judge of the PPT, which we attribute to the source being most plausibly interpreted as the referent with the relevant kind of first-person experience (as proposed in prior work). However, as Figure 3 shows, we find no evidence for an absolute shifttogether constraint that yokes together the judge of PPTs and the antecedent of perspectival pronouns or reflexives. This being said, recall that the antecedent choices of reflexives are sensitive not only to subjecthood but also to source-ofinformation. This source sensitivity resembles the strong source bias that guides PPT judge identification. As a consequence, on average, reflexive conditions appear to exhibit a somewhat closer match between judge identification and antecedent choice than pronouns, but this is by no means a perfect correspondence.

\section{Follow-up experiments}

\subsection{A potential concern: Multiple judges, multiple opinion-holders?}

Here, I briefly report two additional experiments that tackle questions left open by the first experiment, having to do with (i) issues concerning multiple judges and (ii) the syntactic configuration of the anaphors and their antecedents.

A potential concern with the results presented so far is that on each trial, participants could only choose one judge/opinion-holder - namely the subject, the object or the narrator. It was not possible to select multiple judges for the PPT. This raises the question of whether the dissociation discussed above could be an artifact of the 'singe answer choice' format that was used. If we allow participants to choose multiple judges, would we find evidence of judge identification correlating with sources in the case of reflexives and perceivers in the case of pronouns?

A follow-up study was conducted to address this concern. The design was the same as above, except that now, for 'whose opinion' questions, participants were instructed to select "all that apply" - in other words, they could select as many as opinion-holders as they wanted (rather than just one). The 'who shown' question was the same as in the earlier experiment. The same target and filler items were used. We analyzed data from 42 new participants. The results largely replicate the outcome of the experiment reported in Sections 4-6. For the 'who shown' questions, we again see that (i) reflexives tend to be interpreted as referring to the preceding subject and exhibit a numerical source preference, and (ii) pronouns elicit more object interpretations than reflexives and also show a significant preference to be interpreted as referring to the perceiver (subject of heard, object of told).

For the 'whose opinion' questions, where people could now select multiple answers, the results show they still mostly opt for only a single answer: Averaging across conditions, participants chose only one judge on $73 \%$ of all trials. More specifically, participants still prefer the single source-of-information individual 
(subject of told, object of heard) as the judge in all conditions. In line with the first experiment, the pronoun, reflexive condition and no-anaphor conditions all show a preference for the single source-of-information referent (p's $<.001$ ). The proportion of 'narrator's opinion' choices is again low and shows no sensitivity to the verb. ${ }^{5}$

As a whole, the follow-up experiment replicates the results we found in the first experiment. This shows that the results reported in Section 5 regarding the judge of the PPT are not an artifact of the single-answer format.

\subsection{Within and across finite clauses}

So far, we focused on contexts where the anaphor and its antecedent are in the same finite clause, to allow for maximum comparability with Kaiser et al. (2009). To see whether our findings extend to contexts where the anaphor and its antecedent are in different finite clauses, I ran another follow-up with sentences like (14):

Nora $\{$ told/heard from $\}$ Amy that there was a frightening photograph \{of herself/her/ $\varnothing\}$ in the newspaper.

Because the pronoun and reflexive are not in the same finite clause as their antecedents, there is no local c-command relation between anaphor and antecedent in sentences like (14). This configuration allows us to test a configuration where reflexives are very clearly not locally bound by the subject (e.g. Nora in (14)). Thus, in this follow-up study, we adjusted the targets to create two distinct finite clauses. The set-up was the same as above: Participants answered questions about (i) who is shown in the photograph and (ii) whose opinion it is that the photograph is frightening/funny/etc. As in the first follow-up experiment, participants could select multiple answers for the 'whose opinion' question.

The results of the second follow-up experiment (42 new participants) again largely replicate the outcome of the experiment reported in Sections 4-6. Responses to the 'who shown' questions indicate that (i) reflexives tend to be interpreted as referring to the preceding subject but this preference is modulated by a significant source preference (more subject choices with told than heard), while (ii) pronouns elicit more object interpretations than reflexives and also show a significant preference to be interpreted as referring to the perceiver of information (subject of heard, object of told). Responses to the 'whose opinion' questions reveal a clear preference to opt for the single source-of-information referent (subject with told, object with heard) as the judge in all conditions. The pronoun condition, the reflexive condition and the no-anaphor condition all show this preference for the

\footnotetext{
${ }^{5}$ Interestingly, we do find hints of the narrator playing a privileged role as an additional judge: Although people prefer to select the single source-of-information character as the judge, they also occasionally select both the source character and the narrator as the judge ( $16 \%$ of trials, on average).
} 
single source-of-information referent (averaging across all conditions: $88 \%$ source choices, range $76-93 \%$ ). Thus, the results fit with the two preceding studies.

\section{General discussion and conclusions}

This paper set out to investigate the interpretation of subjective adjectives (predicates of personal taste, PPTs), and pronouns and reflexives in the picture-NP construction. Both of these sets of expressions are, in a broad sense, perspectivesensitive: PPTs like fun and irritating express people's opinions and are anchored to an opinion-holder or judge. Reflexives and pronouns in picture-NPs (picture of her/herself) are sensitive to the arguably perspectival distinction between the source vs. the perceiver of information in a communicative events. The present paper reports experimental work investigating whether these two classes of expressions exhibit shift-together behaviors in sentences like (13-14) - i.e. whether they refer to the same perspective center (see e.g. the shift-together constraint proposed by Bylinina et al. 2014, as well as discussion in Sells 1987, Charnavel 2020, i.a.).

Results from three experiments (i) corroborate our earlier findings that reflexives and pronouns in picture-NPs show divergent and asymmetric sensitivity to source and perceiver status (and grammatical role), and (ii) reveal a strong preference to interpret the source of information as the judge of the PPT, regardless of whether an anaphor (pronoun or reflexive) is present. Thus, (iii) we find no evidence for a clear shift-together constraint that would yoke together the judge of PPTs and the antecedent of perspective-sensitive pronouns or reflexives.

Our results pose a challenge to approaches where perspective shifts would be accomplished by a single high-level shifting operator (OP), very schematically illustrated in (15a). In this configuration we would expect all relevant perspectivesensitive elements to be interpreted relative to the same perspectival center, which is not what we found. However, one may wonder about the possibility of multiple smaller perspectival domains. In (15b), the prepositional phrase constitutes its own perspectival domain inside the picture-NP, and thus can show perspectival behavior distinct from the PPT (see also Charnavel 2020 on spell-out domains). A proper discussion of this issue is beyond the scope of this paper, but it's important to note that we need a systematic way to prevent overgeneration of perspectival domains.

$$
\begin{aligned}
& \text { a. OP [frightening photograph of herself ] } \\
& \text { b. OP [frightening photograph OP [of herself]] }
\end{aligned}
$$

Clearly, many intriguing questions remain open for future work, including but not limited to questions concerning the size of the relevant perspectival domain, the nature and extent of crosslinguistic variation in domain size, and the behavior of anaphoric forms in languages with a richer inventory of distinct forms than English. 


\section{References}

Anand, Pranav \& Korotkova, Natasha 2016. Predicates of personal taste and 'de re' construal. Talk given at the Perspectivization workshop at GLOW 39, University of Göttingen, Germany.

Anand, Pranav \& Korotkova, Natasha 2020. How to theorize about subjective meaning: A lesson from 'de re'. Ms. lingbuzz/005361

Anand, Pranav \& Nevins, Andrew. 2004. Shifty operators in changing contexts. Semantics and Linguistic Theory (SALT) 14, 20-37. Ithaca, NY: CLC.

Anand, Pranav. 2009. Kinds of taste. Ms., UCSC.

Bylinina, Lisa. 2014. The Grammar of Standards. PhD Dissertation, Utrecht Institute for Linguistics.

Bylinina, Lisa, McCready, Elin \& Sudo, Yasutada. 2014. The landscape of perspective shifting. Presented at the workshop on Pronouns in Embedded Contexts at the Syntax-Semantics Interface, University of Tuebingen

Cantrall, William, R. 1974. Viewpoint, reflexives, and the nature of noun phrases. The Hague: Mouton.

Cappelen, Herman \& Hawthorne, John. 2009. Relativism and monadic truth. Oxford: Oxford University Press. doi: 10.1093/acprof:oso/9780199560554.001.0001

Charnavel, Isabelle. 2020. Logophoricity and locality: A view from French anaphors. Linguistic Inquiry 51(4), 671-723. doi:10.1162/ling_a_00349

Chomsky, Noam. 1981. Lectures on government and binding. Dordrecht: Foris.

Chomsky, Noam. 1986. Barriers. Cambridge, MA: MIT Press.

Clements, G.N. 1975. The logophoric pronoun in Ewe. Journal of West African Languages 2:141-177.

Coppock, Elizabeth. 2018. Outlook-based semantics. Linguistics and Philosophy 41(2), 125-164. doi:10.1007/s10988-017-9222-y

Culy, Christopher. 1994. Aspects of logophoric marking. Linguistics 32:10551094.

Deal, Amy Rose. 2020. 2020. A theory of indexical shift: meaning, grammar, and crosslinguistic variation. MIT Press. (Linguistic Inquiry Monographs no. 82)

Deal, Amy Rose \& O'Connor, Catherine. 2011. The perspectival basis of fluid-S case-marking in Northern Pomo. In Suzy Lima (ed.), Proceedings of the Fifth Conference on the Semantics of Under-Represented Languages in the Americas (SULA 5). Amherst: GLSA.

Fludernik, Monika. 1993. The Fictions of Language and the Languages of Fiction. The Linguistic Representation of Speech and Consciousness. Routledge.

Frajzyngier, Zygmunt. 1993. A Grammar of Mupun. Berlin: Dietrich Reimer Verlag. 
Glanzberg, Michael. 2007. Context, content, and relativism. Philosophical Studies 136(1), 1-29. doi:10.1007/s11098-007-9145-5

Hagège, Claude. 1974. Les pronoms logophoriques. BSLP, 69:287-310

Huang, Yan. 2000. Anaphora: A cross-linguistic Approach. Oxford University Press.

Jackendoff, Ray. 1972. Semantic interpretation in generative grammar. Cambridge, MA: MIT Press

Kaiser, Elsi. 2015. Perspective-shifting and free indirect discourse: Experimental investigations. In Semantics and Linguistic Theory 25 (SALT 25), 346-372. Ithaca, NY: CLC.

Kaiser, Elsi, Runner, Jeffrey, Sussman, Rachel \& Tanenhaus, Michael. 2009. Structural and semantic constraints on the resolution of pronouns and reflexives. Cognition, 112:55-80. doi: 10.1016/j.cognition.2009.03.010

Keller, Frank \& Asudeh, Ash. 2001. Constraints on linguistic coreference: Structural vs. pragmatic factors. In J. Moore \& K. Stenning (eds.), Proceedings of 23rd annual conference of the cognitive science society, 483488. Mahwah, NJ: L. Erlbaum.

Kennedy, Chris \& Willer, Malte. 2016. Subjective attitudes and counterstance contingency. In Semantics and Linguistic Theory (SALT) 26: 913-933. Ithaca, NY: CLC.

Kneer, Markus, Vicente, Agustin \& Zeman, Dan. 2017. Relativism about predicates of personal taste and perspectival plurality. Linguistics and Philosophy 40, 37-60. doi:10.1007/s10988-016-9198-z

Kuno, Susumo. 1987. Functional syntax: Anaphora, discourse and empathy. Chicago: University of Chicago Press.

Lasersohn, Peter. 2005. Context dependence, disagreement, and predicates of personal taste. Linguistics and Philosophy 28(6), 643-686. doi: 10.1007/s10988-005-0596-x

MacFarlane, John. 2014. Assessment Sensitivity: Relative Truth and its Applications. Oxford: Oxford University Press. doi: 10.1093/acprof:oso/9780199682751.001.0001

McCready, Elin. 2007. Context shifting in questions and elsewhere. In E. PuigWaldmüller (ed.), Proceedings of Sinn und Bedeutung 11, 433-447. Barcelona: Universitat Pompeu Fabra.

McNally, Louise \& Stojanovic, Isidora. 2017. Aesthetic adjectives. In James Young (ed.), The Semantics of Aesthetic Judgments, 17-37. Oxford: Oxford University Press.

Moltmann, Friederike. 2010. Relative truth and the first person. Philos Stud 150:187-220. doi: 10.1007/s11098-009-9383-9

Ninan, Dilip. 2014. Taste predicates and the acquaintance inference. In Semantics and Linguistic Theory (SALT) 24, 290-309. Ithaca, NY: CLC. 
Pearson, Hazel. 2013. A judge-free semantics for predicates of personal taste. Journal of Semantics 30(1), 103-154. doi:10.1093/jos/ffs001

Pearson, Hazel. 2015. The Interpretation of the logophoric pronoun in Ewe. Natural Language Semantics 23(2), 77-118 doi:10.1007/s11050-015-9112-1

Pollard, Carl \& Sag, Ivan. 1992. Anaphors in English and the scope of binding theory. Linguistic Inquiry, 23, 261-303. https://www.jstor.org/stable/4178768

Reinhart, Tanya \& Reuland, Eric. 1993. Reflexivity. Linguistic Inquiry, 24, 657720. https://www.jstor.org/stable/4178836

Rooryck, Johan \& Vanden Wyngaerd, Guido. 2011. Dissolving Binding Theory. Oxford: Oxford University Press. doi: 10.1093/acprof:oso/9780199691326.001.0001

Runner, Jeffrey, Sussman, Rachel \& Tanenhaus, Michael. 2003. Assignment of reference to reflexives and pronouns in picture noun phrases: evidence from eye movements. Cognition, 89(1), B1-B13. doi: 10.1016/S00100277(03)00065-9

Sæbø, Kjell Johan. 2009. Judgment ascriptions. Linguistics and Philosophy 32(4), 327-352. doi: 10.1007/s10988-009-9063-4

Sells, Peter. 1987. Aspects of logophoricity. Linguistic Inquiry, 18(3), 445-479.

Sloggett, Shayne. 2017. When errors aren't: How comprehenders selectively violate Binding Theory. Ph.D. dissertation, UMass Amherst.

Snyder, Eric. 2013. Binding, genericity, and predicates of personal taste, Inquiry, 56:2-3, 278-306. doi: 10.1080/0020174X.2013.784485

Stephenson, Tamina. 2005. Assessor sensitivity: Epistemic modals and predicates of personal taste. In J. Gajewski, V. Hacquard, B. Nickel, \& S. Yalcin (Eds.), New work on modality, MIT working papers in linguistics. vol. 51, 179-206. Cambridge, MA: MITWPL.

Stephenson, Tamina. 2007. Towards a theory of subjective meaning. $\mathrm{PhD}$ dissertation, MIT.

Sundaresan, Sandhya. 2021. Shifty attitudes: indexical shift vs. perspectival anaphora. Annual Review of Linguistics, Vol. 7. 235-259. doi:

10.1146/annurev-linguistics-051220-043921

Tenny, Carol. 2003. Short distance pronouns in representational noun phrases and a grammar of sentience. Ms. www.linguist.org

Tenny, Carol. 2004. Pronoun binding and the grammar of sentience. Talk presented at the Workshop on Semantic Approaches to Binding Theory, held at the 16th European Summer School in Logic, Language and Information, Nancy, France.

Willer, Malte \& Kennedy, Chris. (2020) Assertion, expression, experience. Inquiry. doi:10.1080/0020174X.2020.1850338 
Williams, Edwin. 1987. Implicit arguments, the binding theory and control. Natural Language and Linguistic Theory, 5, 151-180. https://www.jstor.org/stable/4047628

Zakkou, Julia. 2019. Denial and retraction: A challenge for theories of taste predicates. Synthese 196, 1555-1573. doi: 10.1007/s11229-017-1520-y

Zribi-Hertz, Anne. 1989. Anaphor binding and narrative point of view: English reflexive pronouns in sentence and discourse. Language, 65(4), 695-727. doi: $10.2307 / 414931$

Elsi Kaiser

Department of Linguistics

University of Southern California

Los Angeles, CA 90089

emkaiser@usc.edu 